Tarih Kültür ve Sanat Araştırmaları Dergisi

Revue des Recherches en Histoire Culture et Art مجلة البحوث التاريخبة و الثقافية والفنية
Vol. 7, No. 4, November 2018

Copyright (C) Karabuk University http://kutaksam.karabuk.edu.tr

\title{
DOI: 10.7596/taksad.v7i4.1850
}

Citation: Galimova, L., Galimov, S., \& Gerasimova, E. (2018). The Development of Tourism in the Republic of Tatarstan: An Investigation on Activities in Modern Fields. Journal of History Culture and Art Research, 7(4), 300-306. doi:http://dx.doi.org/10.7596/taksad.v7i4.1850

\section{The Development of Tourism in the Republic of Tatarstan: An Investigation on Activities in Modern Fields}

\author{
Leysan Galimova ${ }^{1}$, Shamil' Galimov², Ekaterina Gerasimova ${ }^{3}$
}

\begin{abstract}
The development of tourism is an extremely important direction of the economy of Tatarstan, which affects all spheres of modern society, including culture and social life of the region. The exploration and introduction of new fields in the sphere of tourism promotes the main branches of the economy, forcing them to actively rebuild and introduce the latest technologies and compete in the world goods market. All these contribute to the inflow of investments into the economic segments. Each region tries to attract as many tourists as possible, for this purpose it is expedient to determine the main spheres and directions of activity involved in the development of the industry. The paper outlines the main activities for tourism industry organizations, identifies the main problems in the development of tourism, presents the developed certain recommendations for increasing the tourist flow to the republic. The region's successes in promoting the brand of the territory are noted. The role and importance of actualizing the region's identity in the development of tourism are defined. The role of the organization of cooperation between hospitality enterprises (tour operators and travel agencies, accommodation and catering facilities) under the guidance of the State Committee for Tourism is noted, as well as a description of new directions of tourism development in the Republic of Tatarstan is provided.
\end{abstract}

Keywords: Tourism, the Republic of Tatarstan, the State Committee for Tourism, Branding, Destination, Kazan, Tatar Bistaese, "Visit Tatarstan".

\footnotetext{
${ }^{1}$ Associate professor, candidate of science, Institute of International Relations, History and Oriental Studies, Kazan Federal University. E-mail: Leysan.Abinova@mail.ru

$2 \mathrm{PhD}$, associate professor, Institute of International Relations, Kazan Federal University. E-mail: SSGalimov@yandex.ru

${ }^{3}$ Master's degree (student), Institute of International Relations, History and Oriental Studies, Kazan Federal University. E-mail: tourism.kfu@mail.ru
} 


\section{Introduction}

Tourism in the Republic of Tatarstan is recognized at the state level as a priority area of the national economy. Possessing rich natural, cultural and historical resources, the republic faces the challenge of creating a modern tourism industry that can attract foreign and domestic tourists.

In recent years, the development of tourism in the territory of the Republic of Tatarstan provides a large number of opportunities for structures and organizations interested in the development of this industry. The role of the participants is clearly distributed in the tourism services market, and a large number of tasks are set: from the development of domestic tourism to the promotion of the republic's brand on the world stage. The relevant challenge for the Republic of Tatarstan is to work on four areas: branding of territories, promotion of identity, allocation of target groups, and cooperation of state structures with private tourism organizations. The implementation of these directions should stimulate tourism activities in Tatarstan, strengthen the interconnection of tourism with other priority spheres of activity, will favor the increase of the authority of our republic in the world market of tourist services, the replenishment of the state budget and the creation of a powerful tourist base.

\section{Results and Discussion}

The Netherlands specialist in the field of cultural geography and tourism, as well as the employee of Groningen University Jelmer Jeuring in his article "Contradictions in discourse on marketing strategies of regional tourism: the example of the province of Friesland, the Netherlands" identifies such trends, however, in a slightly different aspect. Jeuring studies the marketing of tourist areas and discovers discrepancies in the marketing strategy of regional tourism in the above directions. This paper takes the concept by Jeuring only as a basis for the examples and experience of tourism development in the Republic of Tatarstan.

Creation of a territory brand is a complex process of developing a strategy for promoting destination, and the brand itself becomes an instrument for the competitiveness of the region. Territory branding is a strategy to increase the competitiveness of cities, regions, geographic zones and states with the aim of conquering foreign markets, attracting investors, tourists, new residents [7]. The Republic of Tatarstan has its own brand "Visit Tatarstan". To create a positive image of Tatarstan, active work is carried out in several directions at once. First, in the regular mode, work is being conducted with the information resources of the region on the Internet. The actualization and expansion of the content of the republican tourist portal visit-tatarstan.com continues; Finnish and German were added to the already existing three language versions (Russian, Tatar, English). visit-tatarstan.com is an easy-to-navigate website with highquality pictures and reliable information about sights, events, means of accommodation of the republic. Special attention is paid to promotion in social networks: official pages "VisitTatarstan" operate on Facebook, Instagram and Vkontakte, with the total number of subscribers reaching 20.000 users. Secondly, the production of souvenirs with the "Visit Tatarstan" symbol is carried out: covers for telephones, umbrellas, bags, sweatshirts, socks, postcards, badges and much more. The tourists will be able to buy this kind of products in the office of the Tourist Information Center of Kazan, the "Arysh Mahe" store museum, the "Solntse vnutri Kazani" store in the shopping center Svita Hall, and the Gorodskaya Panorama complex. Thirdly, the promotion of the brand of the Republic of Tatarstan is carried out at the interregional and international levels. These are international tourism exhibitions such as Matka Nordic Travel Fair in Helsinki, Finland and the Arabian Travel Market in Dubai, United Arab Emirates. All of the above is aimed at creating a favorable image of the region for tourists. But it is worth mentioning that this image is created by local residents, private enterprises involved in tourism. It can be 
argued that the target group of internal promotion are residents and entrepreneurs. Therefore, special attention should be focused on cooperation, target groups, and promotion of identity.

The tourism development strategy should be based on the strong characteristics of the region, on its attractive features. The Republic of Tatarstan is a striking example of a region where the identity and authenticity of the people can become an object of tourist attraction [1]. By the way, one aspect distinguishes the republic from other regions of the Russian Federation. For example, language is also an important way of enhancing differentiation as the main force the identity is manifested through. For example, the Tatar language is regarded as an advantage, demonstrating to tourists the uniqueness of the region. Many signs on the streets, in the capital of the republic, the city of Kazan, stations in public transport are dubbed in the Tatar language. Tourists are interested in Tatar, therefore the tour operator of domestic tourism LLC "Tourist Information Center of Kazan" created a walking tour route "Tatar Polyglot", during which guests will learn basic expressions in Tatar, visit the new interactive museum "Tatar Bistaese", will receive a souvenir and try the dishes of the national Tatar cuisine. The first excursion started in October 2017 and has been visited by more than 60 people for six months.

National Tatar cuisine is also part of the region's identity. Over the past 10 years a large number of cafes and restaurants of the national Tatar cuisine have been established in the city of Kazan only; in addition, its elements can be found in the usual places of the city. Tourists are also attracted by the opportunity to learn the technology of cooking certain dishes, so various excursions and master classes have become popular, where guests learn about the subtleties of cooking, and can also practice everything. For example, the gastronomic excursion "Kazan vkusov" ("A kettle of tastes") includes tea-drinking in the tea museum "Chak-chaka", a master class on cooking triangles - ochpochmaks, and tasting of alcoholic products by "Arysh Mahe". In August 2017, Kazan launched the project "Gastronomic Map of Russia", implemented with the support of the Federal Agency for Tourism. The goal of the project is the development of gastronomic tourism and the promotion of dishes of national cuisine of the regions. The gastronomic map of Russia will note the local production companies, symbolic dishes of regional cuisine, restaurants, cafes and national recipes. Interactive map will be posted on the portal Russia.travel. Thus, it can be concluded that the identity of the Republic of Tatarstan definitely can be considered an aspect of the promotion of the region, and the image of the republic depends on the competent promotion of identity.

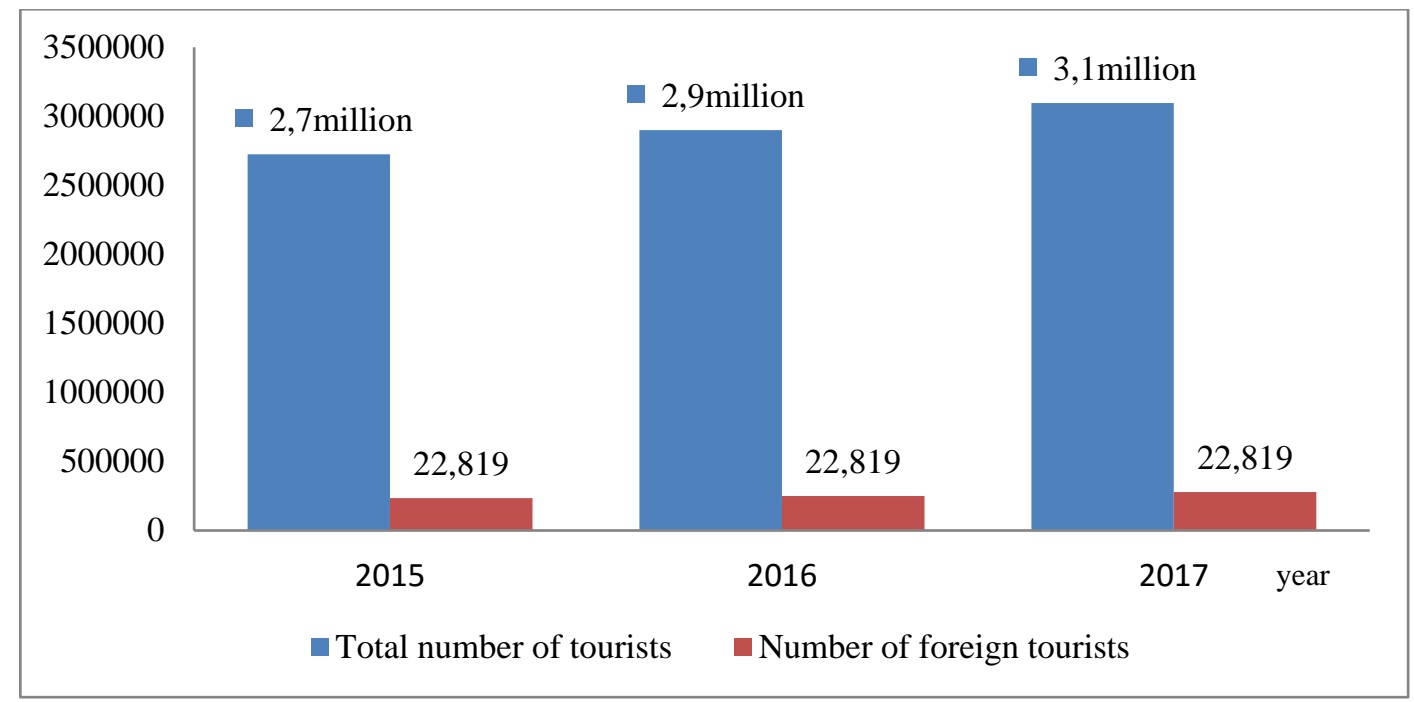

Fig. 1. Dynamics of the tourist flow to the Republic of Tatarstan [4] 
Identifying potential tourists is an important element in creating the image of the destination and managing it. There is a general tendency, during which the preference is given to incoming visitors: more and more foreign tourists come to Tatarstan for business and cultural-cognitive purposes. Although at present a relatively small number of foreigners come to the region (Figure 1); experts emphasize that foreign visitors will be the impetus for the growth of the market [4]. Thus, Tatarstan is increasingly trying to strengthen its position as a destination, connected both with domestic and inbound tourism.

Target groups are part of the classification of certain types of tourists and tourism. At the same time, the formation of target groups can be a stereotyped model based on generalized demand, behavior or other distinctive features. ANO the Tourism Development Center of the Republic of Tatarstan distinguishes target groups of tourists visiting the Republic of Tatarstan by the purposes of the trip: tourists participating in sports competitions, tourists visiting the republic in transit, arriving for treatment, pilgrimage, recreation, and as a business trip and visiting relatives (Fig. 2) [8].

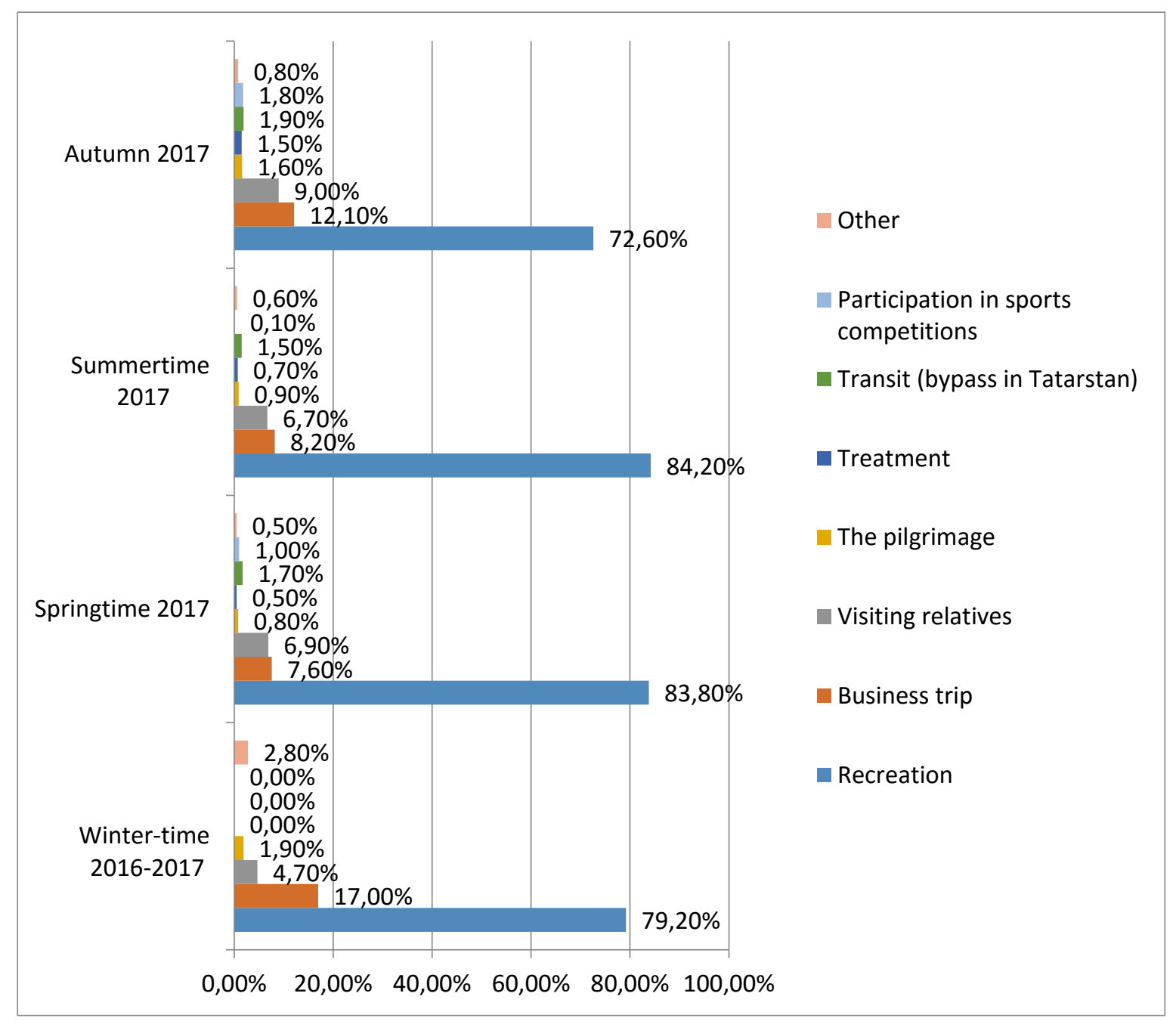

Fig. 2. Purpose of the trip to the Republic of Tatarstan [8]

Tourist trips to the Republic of Tatarstan vary considerably by purpose: there is a clear predominance of recreation over $70 \%$. Business trips (12\%) rank second, often organized without the involvement of travel agencies.

The duration of travel of tourists in the vast majority of cases does not exceed 2 nights. For domestic tourism in Tatarstan, as well as for tourism in other regions of Russia, there is a pronounced seasonality of travel. The share of summer months and winter "kaniku" accounts for $65 \%$ of all served tourists in 
domestic tourism. The tourist mobility of the population is especially high in the summer. During this period, statistics registers almost half of all domestic tourists.

In recent years, within the framework of the preparation for major sporting events, Tatarstan has an attractive material tourism base: as the chart shows, the new hotel complexes have been built, the existing hotel fund of the republic has been renovated by $87 \%$.

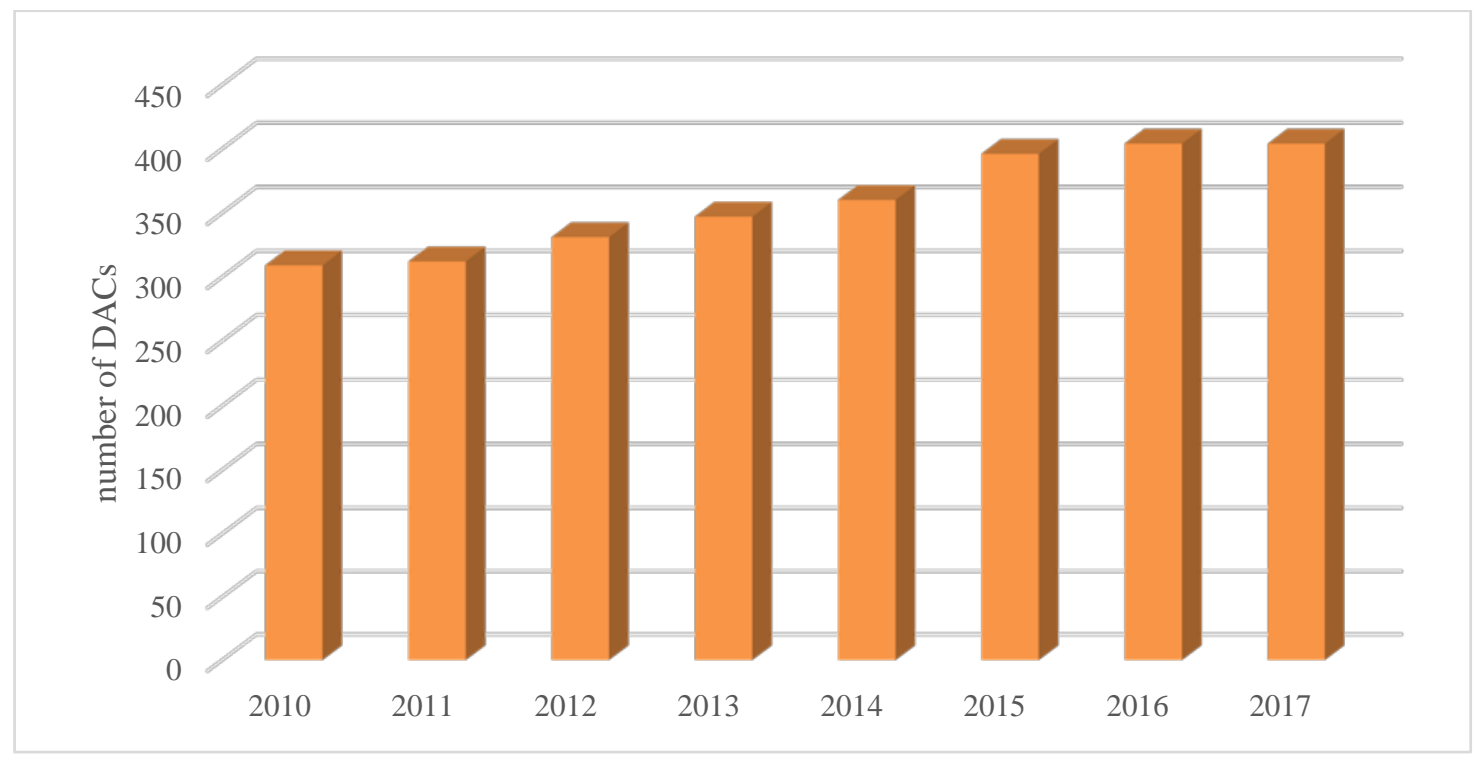

Fig. 3. Dynamics of the number of collective accommodation facilities [4]

We should note the importance of the integrated development of the tourist infrastructure, including the accompanying infrastructure (transport, food enterprises, entertainment industries, tourist display facilities, etc.); for the positive effect and economic feasibility, it is necessary to organize work in the format of cooperation. A vivid example of cooperation of tourism industry organizations in the Republic of Tatarstan is the cooperation of Kazan hotels with the tour operator of domestic tourism LLC "Tourist Information Center of Kazan". Free city maps for guests, flyers with a schedule of excursions, events for each month of the year, as well as the manager of the Tourist Center, which is located in the hotel, can advise guests. Hotels in turn can attract customers with an additional option in the form of booking excursions (on the sites of many Kazan hotels you can see a widget for booking and payment for excursions).

In order to improve the quality of tourism services, the State Committee for Tourism of the Republic of Tatarstan conducts activities to increase the number of hotels with categories in the region, supports the existence of accommodation facilities such as hostels being highly popular among young people. It introduces the beach classification system and takes part in the development of professional service standards by creating the inclusion of employers' requirements in the form of professional standards in educational training programs for the tourism industry.

Subject to the nature of the tourist resources, the state of the tourist infrastructure and the readiness of the tourist product, such kinds of tourism as cultural, cognitive, business, and specialized tourism (event, ecological, rural) are of special interest for the development of inbound and internal tourism to our republic [1].

Given the climatic and landscape features of Tatarstan, it is especially important for the domestic market to develop health and ski tourism. The development of specialized tourism as a new alternative direction is of the greatest interest from the point of view of attracting an experienced foreign consumer and diversifying the domestic tourist offer. 


\section{Conclusions}

Thus, based on the above examples, it can be concluded that the identified priority types of tourism and cooperation of tourism industry organizations can bring benefits to all stakeholders in the form of a growing flow of tourists to the region.

The development of tourism in any region is a strictly internal process, requiring the attention of all participants interested in the development of tourism. Lack of attention to any of the fields of tourism development described in the paper will lead to disorganization of the system in general, as well as to the unfavorable image of the region.

\section{Footnotes}

[1] Abinova, L. I. (2010). Some aspects of tourism development in the regions (based on the example of RT). Today and tomorrow of the Russian economy, 33, 164-166

[2] Galimova, L. I. (2016). Development of tourist clusters in the Volga-Kama basin of the Republic of Tatarstan, Modern science: actual problems of theory and practice. Series "Economics and Law", 3, 7-12.

[3] Gerasimova, E. A., \& Galimova, L. I. (2017). The current state of excursion tourism in the Republic of Tatarstan. Collection: Youth. Tourism. Education. Proceedings of IV scientific-practical on- and off-site conference for schoolchildren, teachers and students, (pp.56-59). Kazan.

[4] State Committee of the Republic of Tatarstan for Tourism. Official Tatarstan (2018). URL: http://tourism.tatarstan.ru/

[5] The results of the work of the State Committee of the Republic of Tatarstan for Tourism for 2017 (Information materials) (2018). Kazan.

[6] Visit Tatarstan (2018). URL: http://visit-tatarstan.com

[7] Eidelman, B. M., Bunakov, O. A., Galimov, S. S., Galimova, L. I., \& Rozhko, M. V. (2015). City branding in Russia: Main trends, problems and development prospects. Social Sciences and Interdisciplinary Behavior: The 4th International Congress on Interdisciplinary Behavior and Social Science (ICIBSoS 2015), (pp.149-151). Kazan Federal University, Kazan, Russia, 22-23 October.

[8] Center for Tourism Development of the Republic of Tatarstan (2018). URL: http://tdc-tatar.ru

[9] Jeuring, J. H. G. (2016). Discursive contradictions in regional tourism marketing strategies: The case of Fryslân, The Netherlands. Journal of Destination Marketing \& Management, 65-75.

[10] Miller, D., \& Freisen, P. H. (1980). Momentum and revolution in Organizational Adaptation. Academy of Management Journal, 23, 591-614

[11] Tourist and information center of Kazan (2018). URL: http://kazantravel.ru/

\section{References}

Abinova, L. I. (2010). Some aspects of tourism development in the regions (based on the example of RT). Today and tomorrow of the Russian economy, 33, 164-166

Center for Tourism Development of the Republic of Tatarstan (2018). URL: http://tdc-tatar.ru 
Eidelman, B. M.; Bunakov, O. A.; Galimov, S. S.; Galimova, L. I. \& Rozhko, M. V. (2015). City branding in Russia: Main trends, problems and development prospects. Social Sciences and Interdisciplinary Behavior: The 4th International Congress on Interdisciplinary Behavior and Social Science (ICIBSoS 2015), (pp.149151). Kazan Federal University, Kazan, Russia, 22-23 October.

Galimova, L. I. (2016). Development of tourist clusters in the Volga-Kama basin of the Republic of Tatarstan, Modern science: actual problems of theory and practice. Series "Economics and Law", 3, 7-12.

Gerasimova, E. A. \& Galimova, L. I. (2017). The current state of excursion tourism in the Republic of Tatarstan. Collection: Youth. Tourism. Education. Proceedings of IV scientific-practical on- and off-site conference for schoolchildren, teachers and students, (pp.56-59). Kazan.

Jeuring, J. H. G. (2016). Discursive contradictions in regional tourism marketing strategies: The case of Fryslân, The Netherlands. Journal of Destination Marketing \& Management, 65-75.

Miller, D. \& Freisen, P. H. (1980). Momentum and revolution in Organizational Adaptation. Academy of Management Journal, 23, 591-614

State Committee of the Republic of Tatarstan for Tourism. Official Tatarstan (2018). URL: http://tourism.tatarstan.ru/

The results of the work of the State Committee of the Republic of Tatarstan for Tourism for 2017 (Information materials) (2018). Kazan.

Tourist and information center of Kazan (2018). URL: http://kazantravel.ru/

Visit Tatarstan (2018). URL: http://visit-tatarstan.com 